\title{
Predictors of preconceptional folic acid or multivitamin supplement use: a cross-sectional study of Danish pregnancy planners
}

This article was published in the following Dove Press journal:

Clinical Epidemiology

4 October 2012

Number of times this article has been viewed

\author{
Heidi T Cueto' \\ Anders H Riis' \\ Elizabeth E Hatch ${ }^{2}$ \\ Lauren A Wise ${ }^{2,4}$ \\ Kenneth J Rothman ${ }^{2,3}$ \\ Ellen M Mikkelsen' \\ 'Department of Clinical Epidemiology, \\ Aarhus University Hospital, \\ Aarhus, Denmark; ${ }^{2}$ Department \\ of Epidemiology, Boston University \\ School of Public Health, Boston, \\ MA, USA; ${ }^{3}$ RTI Health Solutions, \\ Research Triangle Park, NC, USA; \\ ${ }^{4}$ Slone Epidemiology Center, Boston \\ University, Boston, MA, USA
}

Purpose: Compliance with the Danish preconceptional folic acid (FA) recommendation a daily supplement of $400 \mu \mathrm{g}$ - is reported to be poor. Uncertainty remains, however, about the prevalence of compliers and health-related predictors of compliance in the preconceptional period.

Methods: We used self-reported baseline data from 5383 women, aged 18-40 years, enrolled in an Internet-based prospective cohort study of Danish pregnancy planners during 2007-2011. We estimated the prevalence proportions of FA or multivitamin (MV) use in relation to selected sociodemographic, lifestyle, reproductive, and medical characteristics. Multivariate binomial regression was used to obtain prevalence proportion differences with $95 \%$ confidence intervals for each level of study predictors, adjusted for all other predictors.

Results: Overall, 7.7\% of women used FA supplements, 20.4\% used MV supplements, 34.0\% used both, $1.5 \%$ used other single vitamins or minerals, and $36.4 \%$ did not use any dietary supplements. The prevalence of FA or MV supplement use was higher among older women, women with higher education and income, and women with healthy lifestyle factors such as being a nonsmoker, nondrinker, physically active, maintaining a normal body mass index and having regular pap smears. Greater intercourse frequency and a history of spontaneous abortion were also positively associated with FA or MV supplement use. We found no clear association between use of FA or MV supplements and a diagnosis of hypertension, diabetes, thyroid disease, pelvic inflammatory disease, or chlamydia.

Conclusion: A large proportion of pregnancy planners do not use FA or MV supplements. Pregnancy planners with generally risky lifestyle behaviors are less likely to comply with the FA recommendation.

Keywords: pregnancy, preconceptional supplement use, vitamins, folic acid

\section{Introduction}

In Denmark, women planning to conceive are advised to take a daily supplement of $400 \mu \mathrm{g}$ folic acid (FA) until the 12th week of gestation to reduce the risk of neural tube defects (NTDs). ${ }^{1}$ Starting FA supplementation before conception is an important component of effective prevention of NTDs, since the neural tube closes at gestational week 6 , only a few weeks after the pregnancy may be recognized. ${ }^{2}$ FA is primarily taken as single supplements or as a component of multivitamins (MVs) and other vitamin preparations made for pregnancy planners or pregnant women.

Despite campaigns promoting the FA recommendation in Denmark in 1999 and 2001, women in the preconceptional period appear to have neither adequate dietary intake of folate nor adequate supplementation from FA tablets or MV supplements.
Correspondence: Heidi Theresa Cueto Department of Clinical Epidemiology, Aarhus University Hospital, Olof Palmes Allé 43-45, 8200 Aarhus N, Denmark Tel +4587 I 68234

Fax +4587167215

Email hc@dce.au.dk 
According to the National Survey of Dietary Habits from 2003 to 2008 , only 5-10\% of Danish women of fertile age have a sufficient intake of dietary folate. ${ }^{3}$ The most recent data on periconceptional use of FA supplements in Denmark are from the Danish National Birth Cohort (DNBC). Between 2000 and 2002, the proportion of FA compliers among DNBC participants who planned their pregnancy increased from $14 \%$ to only $22 \%$, and thus remained low even after the campaigns. ${ }^{4,5}$ Several retrospective studies of pregnant women in other countries also reported poor compliance, with $12 \%$ of women in the UK, ${ }^{6} 17 \%$ in Norway, ${ }^{7} 23-30 \%$ in Australia ${ }^{8,9}$ and $44 \%$ in the $\mathrm{US}^{10}$ reporting FA supplement use in the preconception period. In addition, a prospective cohort study reported that only $6 \%$ of the women who became pregnant within 3 months of being interviewed in a general woman's survey in the UK followed the FA recommendation. ${ }^{11}$

In previous studies, young age, low education and income, smoking, overweight, and parity were reported to be predictors of noncompliance..$^{5-8,10}$ To date, no study has examined other health-related predictors of compliance during the preconceptional period, and we lack recent estimates of compliance with the FA recommendation reported from pregnancy planners during the preconceptional period. In the current study, we estimated the prevalence of FA and MV supplement use and identified sociodemographic, lifestyle, reproductive, and medical predictors of such use among Danish pregnancy planners.

\section{Methods \\ Design of the present study}

The present study was a cross-sectional analysis of baseline data from an Internet-based prospective cohort study of Danish pregnancy planners - Snart-Gravid (Soon Pregnant).The study design has been described in detail elsewhere. ${ }^{12,13}$ Briefly, the study was initiated in June 2007. Participants were enrolled via the study website, and data were collected by email and self-administered questionnaires. Recruitment was achieved by a pop-up advertisement placed on a well-known healthrelated website (http://www.netdoktor.dk) and two press releases. Before enrolment, potential participants entering the study website were required to read a consent form and fill in a screening questionnaire in order to confirm eligibility. Further, participants were required to provide a valid email address and their personal civil registry (CPR) number, which is a unique ten-digit personal identification number allowing linkage to a number of nationwide registries. Eligible women were invited to complete a baseline questionnaire and bimonthly follow-up questionnaires for 12 months or until conception occurred, after which active follow-up ended. Participants were initially randomized to receive either a short- or a long-form baseline questionnaire. Completion rates and missing data were similar for both questionnaire versions. ${ }^{13}$

\section{Study population and study period}

Eligible women were Danish residents aged 18-40 years, living in a stable relationship with a male partner, not using birth control, not receiving any type of fertility treatment, and attempting to conceive for no more than 12 months. From June 1, 2007 to August 3, 2011, 5918 women completed the screener and the baseline questionnaire. Of these, one woman did not provide a valid CPR number in the screener, one woman was excluded because she was already pregnant (14 weeks), and 533 women were excluded because they had been attempting to conceive for more than 12 months. In total, 5383 eligible women enrolled in the study during the 4-year study period.

\section{Data collection}

Data on preconceptional use of FA and MV supplements and sociodemographic, lifestyle, reproductive, and medical variables were assessed at baseline.

\section{Assessment of FA and MV supplement use}

In the baseline questionnaire, women were asked "Do you take vitamins on a regular basis - daily or almost every day?", "How long have you been taking vitamins on a regular basis - less than one year, 1-5 years, more than 5 years, or don't know?", and "Which of the following vitamins or minerals do you take on a regular basis - MVs, vitamin A, beta-carotene, vitamin B, vitamin $\mathrm{C}$, vitamin $\mathrm{D}$, vitamin $\mathrm{E}, \mathrm{FA}$, calcium, magnesium, selenium, or other?" Participants who reported "multivitamin" or wrote the name of an MV product were defined "MV users." Similarly, participants who reported "folic acid" or wrote "folate" were defined "FA users." "Users" were defined as women who used either FA supplements, MV supplements, or both. Women who used single-vitamin or mineral supplements other than FA and women who did not take any dietary supplements were defined "nonusers." A total of 197 (3.7\%) women did not answer the initial vitamin question and were also defined as nonusers.

\section{Assessment of potential predictors of FA or MV use}

Participants reported weight, height, physical activity, and smoking history in the baseline questionnaire, allowing 
the calculation of body mass index (BMI), total metabolic equivalents (METs), and pack-years of smoking. BMI was calculated by dividing weight $(\mathrm{kg})$ with height squared $\left(\mathrm{m}^{2}\right)$. METs were estimated by summing the METs from moderate and vigorous physical activity (hours per week multiplied by 3.5 and hours per week multiplied by 7.0 , respectively). ${ }^{14}$ Data on smoking were categorized as pack-years of ever-smoking where 1 pack-year was defined as smoking 20 cigarettes per day in 1 year.

To assess sociodemographic predictors of compliance among pregnancy planners, we examined the association between preconceptional FA or MV supplement use and the following variables: age (categorized as $<25,25-29,30-34$, and $\geq 35$ years), schooling (primary and lower secondary school, high school, and other), vocational training (none, short [ $<3$ years], medium [3-4 years], and long [ $>4$ years]) and total monthly household income $(<12,500,12,500$ $24,999,25,000-39,999,40,000-64,999$, and $\geq 65,000$ DKK/ month). We also examined lifestyle factors that could indicate intense efforts to conceive, such as intercourse frequency (categorized as $<1,1-3$, and $\geq 4$ times per week) and months attempting pregnancy at study entrance $(0-1,2-4,5-6$, and 7-12 months). Furthermore, compliance with other health recommendations, such as attending the national screening program for cervical cancer (pap smear) during the last 3 years (none vs one or more), smoking history (never smoked, $<5$, $5-9$, and $\geq 10$ pack-years), current alcohol intake (none, 1-3, $4-7,8-14$, and $\geq 15$ drinks/week), BMI ( $<18.5,18.5-24.9$, 25-29.9, 30-34.9, and $\left.\geq 35 \mathrm{~kg} / \mathrm{m}^{2}\right)$, and engagement in physical activity ( $<10,10-19,20-39$, and $\geq 40$ METs/week), were also of interest. Finally, we studied the associations with previous spontaneous abortion (yes vs no), parity (nulliparous vs parous), and medical conditions that may increase health awareness in relation to pregnancy, which included hypertension (yes vs no), diabetes (yes vs no), thyroid disease (yes vs no), pelvic inflammatory disease (yes vs no), and infection with chlamydia (yes vs no).

\section{Data analysis}

We estimated the prevalence proportion (PP) of FA or MV users in each level of study predictors. Multivariate binomial regression was used to obtain prevalence proportion differences (PPDs) with 95\% confidence intervals (CIs) for each predictor level in relation to the reference group. The multivariate analyses for the PP and PPD for each study predictor were adjusted for all other covariates. Stata statistical software (version 11.2; College Station, Texas) was used for all analyses.
Missing values ranged between $0.1 \%$ (schooling) and $8.7 \%$ (total monthly household income). Because 1540 (28.6\%) participants were initially randomized to receive the short-form baseline questionnaire, they did not receive the questions about hypertension, diabetes, thyroid disease, and pelvic inflammatory disease. For the analyses, we used multiple imputation methods to impute all missing values..$^{15,16}$

\section{Results}

Overall, 412 (7.7\%) women used FA supplements exclusively, 1100 (20.4\%) used MV supplements exclusively, and 1831 (34.0\%) used both, yielding $62.1 \%$ users. A total of $82(1.5 \%)$ used single vitamins or minerals other than FA, and 1958 (36.4\%) did not use any dietary supplements, yielding 2040 (37.9\%) nonusers of FA or MV supplements (Table 1). Among users, $57 \%$ had used supplements for less than 1 year.

Median age was 28 years for both users and nonusers. After mutual adjustment for covariates, higher age was associated with increased prevalence of FA or MV use (Table 2). Our data also indicate that women who finished high school were more likely to use FA or MVs compared with women with less schooling. Similarly, compared with women with a long vocational training ( $>4$ years), PPDs for having no vocational training and a short ( $<3$ years) vocational training were $-5.7 \%$ and $-7.1 \%$, respectively, and compared with total monthly household of $\geq 65,000 \mathrm{DKK} /$ month, PPD for $<12,500 \mathrm{DKK} /$ month was $-8.7 \%$.

While intercourse frequency $\geq 1$ times/week was associated with an increased prevalence of FA or MV use, there was no clear association between months attempting to conceive at study entrance and FA or MV use. Furthermore, women who had pap smears once or more during the last 3 years were more likely to use FA or MV supplements compared with women who did not have pap smears (PPD was $-9.7 \%$ for none versus one or more).

Smoking, alcohol use, and obesity (BMI $\left.\geq 30 \mathrm{~kg} / \mathrm{m}^{2}\right)$ were associated with a decreased prevalence of FA or MV use. Compared with women who never smoked, PPD for $\geq 10$ pack-years of smoking was $-11.3 \%$. Compared with

Table I Dietary supplement use among 5383 pregnancy planners

\begin{tabular}{lll}
\hline & $\mathbf{n}$ & $\mathbf{( \% )}$ \\
\hline Users & & \\
$\quad$ Folic acid exclusive & 412 & $(7.7)$ \\
$\quad$ Multivitamins exclusive & 1100 & $(20.4)$ \\
$\quad$ Folic acid and multivitamins & 1831 & $(34.0)$ \\
Nonusers & & \\
No use & 1958 & $(36.4)$ \\
Other vitamins and minerals exclusive & 82 & $(1.5)$ \\
\hline
\end{tabular}


Table 2 Prevalence proportions (PPs), prevalence-proportion differences (PPDs) with 95\% confidence intervals (Cls) of folic acid or multivitamin supplement use in relation to sociodemographic, lifestyle, reproductive, and medical characteristics, respectively in 5383 women

\begin{tabular}{|c|c|c|c|c|c|c|}
\hline \multirow[t]{2}{*}{ Characteristics } & \multirow{2}{*}{$\frac{\text { Nonusers }}{\mathrm{n}(2040)}$} & \multirow{2}{*}{$\begin{array}{l}\text { Users } \\
\text { n (3343) }\end{array}$} & \multirow{2}{*}{$\begin{array}{l}\text { Unadjusted } \\
\text { PP (\%) }\end{array}$} & \multicolumn{3}{|c|}{ Adjusted $^{\mathrm{a}}$} \\
\hline & & & & PP (\%) & PPD (\%) & $95 \% \mathrm{Cl}$ \\
\hline \multicolumn{7}{|l|}{ Sociodemographic factors } \\
\hline \multicolumn{7}{|l|}{ Age, years } \\
\hline$<25$ & 461 & 507 & 52.4 & 58.8 & -5.2 & $-1 \mathrm{I} .6, \mathrm{I} . \mathrm{I}$ \\
\hline $25-29$ & 882 & 1515 & 63.2 & 62.5 & -1.6 & $-6.7,3.5$ \\
\hline $30-34$ & 518 & 1037 & 66.7 & 66.7 & 2.7 & $-2.3,7.6$ \\
\hline$\geq 35$ & 179 & 284 & 61.3 & 64.1 & Ref & 0 \\
\hline \multicolumn{7}{|l|}{ Schooling } \\
\hline Primary/lower secondary school & 387 & 405 & 51.1 & 56.6 & -5.9 & $-10.0,-1.8$ \\
\hline High school & 1386 & 2612 & 65.3 & 62.5 & Ref & 0 \\
\hline Other & 267 & 326 & 55.0 & 56.4 & -6.1 & $-10.5,-1.8$ \\
\hline \multicolumn{7}{|l|}{ Vocational training } \\
\hline None & 345 & 379 & 52.4 & 57.4 & -5.7 & $-11.2,-0.2$ \\
\hline Short ( $<3$ years) & 716 & 906 & 55.9 & 56.0 & -7.1 & $-11.2,-3.0$ \\
\hline Medium ( $3-4$ years) & 622 & 1,252 & 66.8 & 62.5 & -0.6 & $-4.3,3.0$ \\
\hline Long ( $>4$ years $)$ & 357 & 806 & 69.3 & 63.1 & Ref & 0 \\
\hline \multicolumn{7}{|l|}{ Household income, DKK/month } \\
\hline$<12,500$ & 64 & 64 & 50.0 & 51.8 & -8.7 & $-19.8,2.2$ \\
\hline $12,500-24,999$ & 280 & 370 & 56.9 & 61.8 & 1.2 & $-4.8,7.3$ \\
\hline $25,000-39,999$ & 552 & 805 & 59.3 & 61.8 & 1.2 & $-3.5,5.8$ \\
\hline $40,000-64,999$ & 854 & 1572 & 64.8 & 62.5 & 1.9 & $-3.5,5.8$ \\
\hline$\geq 65,000$ & 290 & 532 & 64.7 & 60.6 & Ref & 0 \\
\hline \multicolumn{7}{|l|}{ Lifestyle factors } \\
\hline \multicolumn{7}{|l|}{ Intercourse frequency, times/week } \\
\hline$<1$ & 392 & 495 & 55.8 & 54.7 & -5.9 & $-10.3,-1.5$ \\
\hline $1-3$ & 1236 & 2217 & 64.2 & 62.5 & 1.8 & $-1.5,5.1$ \\
\hline$\geq 4$ & 412 & 631 & 60.5 & 60.7 & Ref & 0 \\
\hline \multicolumn{7}{|l|}{ Attempting pregnancy, months } \\
\hline $0-1$ & 868 & 1457 & 62.7 & 62.5 & Ref & 0 \\
\hline $2-4$ & 569 & 994 & 63.6 & 65.0 & 2.5 & $-0.5,5.5$ \\
\hline $5-6$ & 252 & 372 & 59.6 & 61.3 & -1.1 & $-5.4,3.2$ \\
\hline $7-12$ & 351 & 520 & 59.7 & 61.3 & -1.1 & $-4.9,2.6$ \\
\hline \multicolumn{7}{|l|}{ Pap smears ${ }^{\mathrm{b}}$, last 3 years } \\
\hline None & 545 & 556 & 50.5 & 62.5 & -9.7 & $-13.2,-6.2$ \\
\hline$\geq 1$ & 1495 & 2787 & 65.1 & 72.2 & Ref & 0 \\
\hline \multicolumn{7}{|l|}{ Smoking status, pack-years } \\
\hline Never smoked & 1052 & 2097 & 66.6 & 62.5 & Ref & 0 \\
\hline$<5$ & 526 & 726 & 58.0 & 58.1 & -4.3 & $-7.6,-1.1$ \\
\hline $5-9$ & 280 & 327 & 53.9 & 53.1 & -9.4 & $-14.3,-4.7$ \\
\hline$\geq 10$ & 182 & 193 & 51.5 & 51.2 & -11.3 & $-16.8,-5.8$ \\
\hline \multicolumn{7}{|l|}{ Alcohol intake, drinks/week } \\
\hline None & 601 & 1097 & 64.6 & 67.0 & Ref & 0 \\
\hline $1-3$ & 795 & 1404 & 63.9 & 62.5 & -4.5 & $-7.5,-1.5$ \\
\hline $4-7$ & 466 & 602 & 56.4 & 55.4 & -11.6 & $-15.4,-7.8$ \\
\hline $8-14$ & 130 & 204 & 61.1 & 60.3 & -6.7 & $-12.4,-1.0$ \\
\hline$\geq 15$ & 48 & 36 & 42.9 & 48.6 & -18.4 & $-29.1,-7.6$ \\
\hline \multicolumn{7}{|l|}{ BMI, kg/m² } \\
\hline$<18.5$ & 91 & 128 & 58.5 & 65.2 & -2.7 & $-9.4,4.0$ \\
\hline $18.5-24.9$ & 1219 & 2,192 & 64.3 & 62.5 & Ref & 0 \\
\hline $25-29.9$ & 424 & 651 & 60.6 & 63.4 & -1.8 & $-5 . \mathrm{I}, \mathrm{I} .5$ \\
\hline $30-34.9$ & 185 & 239 & 56.4 & 60.1 & -5.1 & $-10.1,-0.1$ \\
\hline$\geq 35$ & 121 & 133 & 52.4 & 58.1 & -7.1 & $-13.4,-0.8$ \\
\hline
\end{tabular}


Table 2 (Continued)

\begin{tabular}{|c|c|c|c|c|c|c|}
\hline \multirow[t]{2}{*}{ Characteristics } & \multirow{2}{*}{$\frac{\text { Nonusers }}{\text { n (2040) }}$} & \multirow{2}{*}{$\begin{array}{l}\text { Users } \\
\text { n (3343) }\end{array}$} & \multirow{2}{*}{$\begin{array}{l}\text { Unadjusted } \\
\text { PP (\%) }\end{array}$} & \multicolumn{3}{|c|}{ Adjusted $^{\mathrm{a}}$} \\
\hline & & & & PP (\%) & PPD (\%) & $95 \% \mathrm{Cl}$ \\
\hline \multicolumn{7}{|c|}{ Physical activity, METs/week } \\
\hline$<10$ & 388 & 476 & 55.1 & 56.5 & Ref & 0 \\
\hline $10-19$ & 649 & 1080 & 62.5 & 62.0 & 5.5 & $1.5,9.4$ \\
\hline $20-39$ & 666 & 1230 & 64.9 & 62.5 & 5.9 & $2.0,9.9$ \\
\hline$\geq 40$ & 337 & 554 & 62.2 & 60.7 & 4.2 & $-0.5,8.8$ \\
\hline \multicolumn{7}{|c|}{ Reproductive history } \\
\hline \multicolumn{7}{|c|}{ Previous spontaneous abortions (\%) } \\
\hline No & 1848 & 2955 & 61.5 & 62.5 & Ref & 0 \\
\hline Yes & 192 & 388 & 66.9 & 70.2 & 7.7 & $3.7,11.8$ \\
\hline \multicolumn{7}{|c|}{ Parous, ever had live birth } \\
\hline No & 1358 & 2234 & 62.2 & 54.2 & Ref & 0 \\
\hline$\geq 1$ & 682 & 1109 & 61.9 & 52.9 & -1.2 & $-4.2,1.9$ \\
\hline \multicolumn{7}{|l|}{ Medical history } \\
\hline \multicolumn{7}{|l|}{ Hypertension (\%) } \\
\hline No & 1303 & 3116 & 62.1 & 62.5 & Ref & 0 \\
\hline Yes & 137 & 227 & 62.4 & 63.4 & I.I & $-6.2,8.4$ \\
\hline \multicolumn{7}{|l|}{ Diabetes (\%) } \\
\hline No & 2020 & 3300 & 62.0 & 54.2 & Ref & 0 \\
\hline Yes & 20 & 43 & 68.3 & 59.7 & 13.8 & $-1.0,28.6$ \\
\hline \multicolumn{7}{|l|}{ Thyroid disease (\%) } \\
\hline No & 1989 & 3263 & 62.1 & 62.5 & Ref & 0 \\
\hline Yes & 51 & 80 & 61.1 & 59.4 & -3.1 & $-15.4,9.2$ \\
\hline \multicolumn{7}{|c|}{ Pelvic inflammatory disease (\%) } \\
\hline No & 1733 & 2905 & 62.6 & 62.5 & Ref & 0 \\
\hline Yes & 307 & 438 & 58.8 & 60.8 & -1.7 & $-5.9,2.6$ \\
\hline \multicolumn{7}{|l|}{ Chlamydia (\%) } \\
\hline No & $159 \mid$ & 2661 & 62.6 & 54.2 & Ref & 0 \\
\hline Yes & 449 & 682 & 60.3 & 54.0 & 0.1 & $-3.0,3.3$ \\
\hline
\end{tabular}

Note: aMutually adjusted for all other covariates. ${ }^{b}$ National screening program for cervical cancer.

no alcohol intake PPD for $\geq 15$ drinks/week was $-18.4 \%$. Compared with normal weight $\left(\mathrm{BMI}=18.5-24.9 \mathrm{~kg} / \mathrm{m}^{2}\right)$, PPDs of FA or MV use for BMIs of 30-34.9 and $\geq 35 \mathrm{~kg} / \mathrm{m}^{2}$ were $-5.1 \%$ and $-7.1 \%$, respectively. Furthermore, women who engaged in physical activity were more likely to use FA or MVs than sedentary women (<10 METs/week).

Among women who had a previous spontaneous abortion, the PPD of FA or MV use was 7.7\% higher than women who did not report having a previous abortion. However, being multiparous was not associated with increased FA or MV use.

Finally, there was no clear association between being diagnosed with either hypertension, diabetes, thyroid disease, pelvic inflammatory disease, or infections with chlamydia and preconceptional FA or MV supplement use.

\section{Discussion}

\section{Prevalence proportions}

Our data indicate that $62 \%$ of the 5383 pregnancy planners in this study adhere to the Danish FA recommendation.
By interpreting "users" as compliers, we may overestimate the proportion of compliers following the FA recommendation. The questionnaire provided information on whether the women took an FA or MV supplement or not, but there was no information on the exact dose of FA ingested or the brand name of the FA or MV product. In addition, $20 \%$ of the women used MVs exclusively. Since MV supplements have no standard definitions, ${ }^{17-20}$ it cannot be assumed that all MVs contained FA. However, most MVs on the Danish market contain $400 \mu \mathrm{g}$ FA, especially those made for use during pregnancy.

No previous study has collected data on FA and MVs during the preconception period. The prevalence among pregnancy planners in our study is higher than the prevalence of preconception FA $(12 \%-44 \%)^{5-10}$ and MV use $(11 \%)^{8}$ reported by pregnant women in previous studies. However, these studies collected data during the second and third trimesters, which may decrease the recall of FA and MV use during the preconceptional period. In addition, the studies were relatively small, with 588 women attending an antenatal 
clinic in Melbourne in gestational weeks 36-38, ${ }^{8} 1541$ women attending an antenatal ultrasound screening in gestational weeks $17-19$ in Oslo, ${ }^{7}$ and 327 pregnant women calling the California Teratogen Information Service in gestational week 13 in the US. ${ }^{10}$ Consequently, prevalence estimates reported in these studies may have been imprecise.

The definition of compliance with the FA recommendation differs among studies. In the study by Forster et al, ${ }^{8} 29 \%$ took prepregnancy FA supplements, but only 23\% reported taking FA for at least 4 weeks before pregnancy. In the study by Braekke and Staff, ${ }^{7} 17 \%$ of the women started the supplementation before the first day of the last menstruation. However, an additional 16\% started FA supplementation at 0-4 weeks of gestation. Thus, 33\% of the women started FA within 4 weeks of gestation. This proportion may be more comparable with our findings, since some "users" in our study may have been in gestational weeks $0-4$ at baseline.

Women with unplanned pregnancies are less likely to use FA supplements before pregnancy. In the studies by Forster et $\mathrm{al}^{8}$ and Goldberg et al, ${ }^{10}$ the prevalence of unplanned pregnancy was $19 \%$ and $36 \%$, respectively. These studies estimated FA use among all pregnancies (planned and unplanned), making their results difficult to compare with ours. In the study by Braekke and Staff, ${ }^{7}$ there was no information about unplanned pregnancies or contributions of FA from MV supplements, both increasing the possibility of underestimation of the proportions of FA users in this study.

In Denmark, the largest and most recent study of lifestyle factors in relation to compliance with the FA recommendation was conducted among 18,294 pregnant women (gestational weeks 10-12) enrolled in the DNBC during 2000-2002.5 In this study, FA supplements were derived from single FA tablets, MV tablets, and vitamins made for pregnant or lactating women. Compliance was defined as taking $320 \mu \mathrm{g}$ FA per day, from 4 weeks before the date of the last menstrual period until gestation week 6 . A total of $76 \%$ of the pregnancies were planned, and the overall proportion of women who complied with the recommendation was only $16 \%$ among planners. During the 10-year time period to the present study, there may have been an increase in the awareness as well as more available information about prepregnant recommendations, which may partly explain the observed increase in the prevalence of compliers with the FA recommendation found in this study. In contrast to the DNBC, our data on supplement use and potential predictors were reported during the preconceptional period, and information was recorded prospectively, which increases the validity of the study. On the other hand,
Snart-Gravid study participants may be more health-conscious than the general population of pregnancy planners, possibly overestimating the prevalence of FA or MV use. Even so, it is unlikely that an overestimation of supplement use would meaningfully distort the associations between predictors and FA or MV use. In addition, differences in sociodemographic factors among Snart-Gravid study participants compared with the general population may also contribute to an overestimation of FA or MV use.

\section{Predictors of FA or MV use}

Our study agrees with previous studies that found that maternal age, ${ }^{5,7,10}$ education, ${ }^{5,6,10}$ income, ${ }^{6,8}$ smoking, ${ }^{5,8}$ and BMI ${ }^{10}$ were associated with preconception FA use. Although a history of childbirth may increase awareness of preconceptional FA use, previous studies found that a previous childbirth either decreased the likelihood of FA use in subsequent pregnancies or was not related to FA use. ${ }^{5,7,8}$ We found only little association between parity and FA use in our study.

The positive associations between previous spontaneous abortion and intercourse frequency and FA or MV use found in our study have not been reported previously. These findings may indicate a relation between a high desire to conceive and increased knowledge about the preconceptional FA guidelines.

While lifestyle recommendations during pregnancy are widely available, less advice is available for women trying to conceive. In addition to the FA recommendation, Danish women planning a pregnancy are advised to avoid alcohol altogether. ${ }^{1}$ A total of $32 \%$ reported no alcohol intake in our study, which was slightly more than the $12 \%$ reported from the DNBC previously. ${ }^{21}$ In addition, we found the lowest proportion of FA or MV users among women with the highest alcohol intake. Together with the concern that excessive alcohol intake impedes the normal bioavailability and metabolism of folate, ${ }^{22}$ these results underscore the need to target women at high risk of not following the FA recommendation, as well as those not following other preconceptional guidelines.

Being diagnosed with a chronic disease has previously been associated with increased dietary supplement use in general. ${ }^{23}$ Pregnancy planners with a chronic illness might be more prone to use FA or MVs because of increased health awareness, but we found little association between a diagnosis of hypertension, diabetes, thyroid disease, pelvic inflammatory disease or infections with chlamydia and preconceptional use of FA or MVs. 


\section{Conclusion}

Our findings indicate that more than one-third of the pregnancy planners in this study do not follow the preconceptional FA recommendation. We found that pregnancy planners with other risky behaviors, such as smoking and alcohol use, obesity, and being physically inactive, are less likely to comply with the FA recommendation or use MVs.

\section{Acknowledgments}

This study was supported by the National Institute of Child Health and Human Development (R21-050264) and the Danish Medical Research Council (271-07-0338).

\section{Disclosure}

The authors report no conflicts of interest in this work.

\section{References}

1. http://www.sundhedsstyrelsen.dk [homepage on the Internet]. Copenhagen: Danish Health and Medicines Authority. Available from: http:// sst.dk. Accessed September 14, 2012.

2. Czeizel AE, Dudas I. Prevention of the first occurrence of neural-tube defects by periconceptional vitamin supplementation. $N$ Engl J Med. 1992;327:1832-1835.

3. Pedersen AN, Fagt S, Groth MV. Danskernes Kostvaner 2003-2008. Søborg: DTU Fødevareinstituttet; 2010.

4. Olsen SF, Michaelsen KF, Rasmussen LB, Knudsen VK. Folsyre til kvinder der planlægger graviditet - kun få følger anbefalingen! Copenhagen: Ernæringsrådet; 2003.

5. Knudsen VK, Orozova-Bekkevold I, Rasmussen LB, Mikkelsen TB, Michaelsen KF, Olsen SF. Low compliance with recommendations on folic acid use in relation to pregnancy: is there a need for fortification? Public Health Nutr. 2004;7:843-850.

6. Brough L, Rees GA, Crawford MA, Dorman EK. Social and ethnic differences in folic acid use preconception and during early pregnancy in the UK: effect on maternal folate status. J Hum Nutr Diet. 2009;22:100-107.

7. Braekke K, Staff AC. Periconceptional use of folic acid supplements in Oslo. Acta Obstet Gynecol Scand. 2003;82:620-627.

8. Forster DA, Wills G, Denning A, Bolger M. The use of folic acid and other vitamins before and during pregnancy in a group of women in Melbourne, Australia. Midwifery. 2009;25:134-146.
9. Conlin ML, MacLennan AH, Broadbent JL. Inadequate compliance with periconceptional folic acid supplementation in South Australia. Aust N Z J Obstet Gynaecol. 2006;46:528-533.

10. Goldberg BB, Alvarado S, Chavez C, et al. Prevalence of periconceptional folic acid use and perceived barriers to the postgestation continuance of supplemental folic acid: survey results from a Teratogen Information Service. Birth Defects Res A Clin Mol Teratol. 2006;76: 193-199.

11. Inskip HM, Crozier SR, Godfrey KM, Borland SE, Cooper C, Robinson SM. Women's compliance with nutrition and lifestyle recommendations before pregnancy: general population cohort study. $B M J$. 2009;338:b481.

12. Mikkelsen EM, Hatch EE, Wise LA, Rothman KJ, Riis A, Sorensen HT. Cohort profile: the Danish Web-based Pregnancy Planning Study 'Snart-Gravid'. Int J Epidemiol. 2009;38:938-943.

13. Rothman KJ, Mikkelsen EM, Riis A, Sorensen HT, Wise LA, Hatch EE. Randomized trial of questionnaire length. Epidemiology. 2009; 20:154.

14. Jacobs DR Jr, Ainsworth BE, Hartman TJ, Leon AS. A simultaneous evaluation of 10 commonly used physical activity questionnaires. Med Sci Sports Exerc. 1993;25:81-91.

15. Donders AR, van der Heijden GJ, Stijnen T, Moons KG. Review: a gentle introduction to imputation of missing values. J Clin Epidemiol. 2006;59:1087-1091.

16. Zhou XH, Eckert GJ, Tierney WM. Multiple imputation in public health research. Stat Med. 2001;20:1541-1549.

17. Becker W, Alexander J, Aro A, et al. Nordic Nutrition Recommendations: Integrating Nutrition and Physical Activity. 4th ed. Copenhagen: Nordic Council Of Ministers; 2004.

18. Knudsen VK, Rasmussen LB, Haraldsdottir J, et al. Use of dietary supplements in Denmark is associated with health and former smoking. Public Health Nutr. 2002;5:463-468.

19. Rock CL. Multivitamin-multimineral supplements: who uses them? Am J Clin Nutr. 2007;85:277S-279S.

20. Yetley EA. Multivitamin and multimineral dietary supplements: definitions, characterization, bioavailability, and drug interactions. Am J Clin Nutr. 2007;85:269S-276S.

21. Juhl M, Nyboe Andersen AM, Gronbaek M, Olsen J. Moderate alcohol consumption and waiting time to pregnancy. Hum Reprod. 2001;16: 2705-2709.

22. Mason JB, Choi SW. Effects of alcohol on folate metabolism: implications for carcinogenesis. Alcohol. 2005;35:235-241.

23. Jasti S, Siega-Riz AM, Bentley ME. Dietary supplement use in the context of health disparities: cultural, ethnic and demographic determinants of use. J Nutr. 2003;133:2010S-2013S.
Clinical Epidemiology

\section{Publish your work in this journal}

Clinical Epidemiology is an international, peer-reviewed, open access journal focusing on disease and drug epidemiology, identification of risk factors and screening procedures to develop optimal preventative initiatives and programs. Specific topics include: diagnosis, prognosis, treatment, screening, prevention, risk factor modification, systematic

\section{Dovepress}

reviews, risk \& safety of medical interventions, epidemiology \& biostatical methods, evaluation of guidelines, translational medicine, health policies \& economic evaluations. The manuscript management system is completely online and includes a very quick and fair peer-review system, which is all easy to use. 